\title{
PERSPECTIVAS SOCIO-ANTROPOLÓGICAS SOBRE EL CAMPO DEL DERECHO Y LA JUSTICIA
}

\section{Graciela Beatriz RODRÍGUEZ ${ }^{1}$}

\section{Resumen:}

Desde un enfoque socio-antropológico del derecho son numerosos los aportes que se están llevando a cabo para desentrañar el complejo entramado del ámbito del derecho. La relevancia de los mismos nos ayudan a focalizar la especificidad de la sociología y antropología jurídicas como, asimismo, sus potencialidades teóricas y metodológicas. En esta dirección, en el presente artículo reflexionamos críticamente sobre algunas de estas contribuciones.

Palabras claves: antropología jurídica - sociología jurídica - derecho - justicia

\begin{abstract}
:
From a socio-anthropological approach to the law, there are many contributions to unravel the complex framework of the law field. Their relevance helps us focus on the specifity of the legal sociology and anthropology as well as their theoretical and methodological potentialities.In this way, in the present article we reflect critically on some of these contributions.
\end{abstract}

Keywords: legal anthropology - legal sociology - law - justice

\section{Résumé :}

Du point de vue socio-anthropologique juridique, ils sont nombreux les apports existants pour déchiffrer la complexité présente autour du domaine juridique. L'importance de ces contributions nous permet de nous centrer sur la spécificité et l'anthropologie juridiques de manière conjointe, ainsi que sur leurs puissances théoriques et méthodologiques. Par rapport à cela, dans cet article on va réfléchir de manière critique quant aux différents apports.

Mots clés: anthropologie juridique - sociologie juridique - justice - juridique

\footnotetext{
${ }^{1}$ Consejo de Investigaciones de la Universidad Nacional de Rosario -CIUNR - / Facultad de Humanidades y Artes, Universidad Nacional de Rosario, Argentina.

E-mail: gbrodrig@fhumyar.unr.edu.ar
}

Fecha de recepción del artículo: Octubre 2010

Fecha de evaluación: Noviembre 2010 


\title{
Consideraciones previas:
}

En el presente artículo reflexionamos críticamente sobre algunos de los aportes que han contribuido a perfilar el campo de los estudios socio-antropológicos acerca del derecho y la justicia. En tal sentido, iniciamos el recorrido dando cuenta de los acuerdos y desacuerdos en torno al mismo concepto de derecho, para luego analizar sus transformaciones en el escenario global. Seguidamente nos detenemos en la mirada antropológica sobre el campo del derecho y la justicia a través de las diferentes épocas y paradigmas que estructuraron estos abordajes. Destacamos, asimismo, los aportes de las visiones pluralistas del derecho y la emergencia de modalidades alternativas de resolución de conflictos en el marco de los Estados nacionales. Éstas últimas procuran un acceso a la justicia de mayor calidad e inclusión social.

En los últimos apartados ponemos de relieve la importancia de incorporar en los estudios sociojuríidcos el análisis de la dimensión simbólica, de las ritualizaciones, de los espacios judiciales y sus jerarquías y del componente emocional que toda disputa o conflicto judicial conlleva. Aspectos, por otra parte, que no presentan un marcado desarrollo en las producciones socioantropológicas de nuestro medio.

\section{1- ¿De qué hablamos cuando hablamos de derecho?}

Los enfoques socio-antropológicos del derecho plantean inmensos desafíos a la hora de establecer las vinculaciones entre las teorías sociológicas o antropológicas con aquello que en un sentido muy amplio se denomina el ámbito de lo jurídico. Claro está, entonces, que debemos partir de una caracterización del mismo concepto de derecho; y veremos que, en este punto, no todos son acuerdos.

Desde la perspectiva de Vincenzo Ferrari (2006), el núcleo de análisis de la sociología del derecho son las normas jurídicas ya que la expresión "derecho" designa un conjunto de normas. Ampliar este concepto a las actividades ligadas a la creación y aplicación de las mismas presupondría que todo aquello que se relacione con las normas es derecho y, por tanto, todo sería derecho. Pero ¿cuál es, entonces, el ámbito de actuación de los sociólogos del derecho desde este punto de vista?. Al respecto Ferrari señala (op.cit.: 45):

\begin{abstract}
"En efecto, debería resultar claro que la sociología del derecho se ocupa de insertar el derecho en el cuadro general ofrecido por la sociología, de comprender sus características y examinar en qué modo este interfiere con otros factores que caracterizan la acción humana". (cursiva en el original).
\end{abstract}

En tal dirección, comprender las características del derecho para Ferrari es centrar el análisis en los sistemas jurídicos ${ }^{2}$ atendiendo a su estructuración, sus funciones, sus relaciones con otros sistemas jurídicos y con la sociedad en su conjunto. Asimismo, es de interés relacionar las acciones y conductas con lo previsto en la normativa jurídica, dar cuenta de los procesos de formación y aplicación del derecho a luz del accionar de los legisladores, jueces y abogados en sus respectivos contextos organizacionales y, a su vez, incorporar la visión ciudadana sobre el

\footnotetext{
2 El concepto "sistema jurídico" ha sido resignificado de cara a las alternativas entre monismo y pluralismo jurídico. El principio de soberanía y total monopolio de cada Estado sobre su propio de derecho se encuentra en entredicho a la luz de nuevas formas de supranacionalidad y de transnacionalidad, por un lado, y del crecimiento de reivindicaciones culturales y étnicas en el seno de las sociedades, por otro. Por tal motivo, desde los enfoques sociológicos del derecho, y aún desde las posiciones de numerosos juristas, se alude a la existencia de varios sistemas jurídicos. Ferrari (op.cit.:85) al respecto se pregunta: ¿cómo negar a los sistemas normativos que nacen y operan por encima y por debajo de los límites del Estado los rasgos de la juridicidad?
} 
contenido de las normas jurídicas en el marco de los valores culturales subyacentes. En este orden de ideas, el derecho es una peculiar modalidad de acción social, y la sociología del derecho la disciplina que da cuenta de esas peculiaridades. Desde la perspectiva del autor no caben dudas de la diferencia entre el análisis de un jurista y el análisis de un antropólogo o sociólogo del derecho. Para el jurista cuenta el estudio del derecho positivo y la aplicación del mismo. El derecho, y en palabras de Ferrari (op.cit.: 18), es el "elemento constante, el presupuesto y el horizonte de su acción. Por el contrario, para el sociólogo el derecho aparece como una variable, que se debe considerar y medir en relación con otras variables que influyen en la acción humana". (cursiva en el original)

En este orden de ideas, el antropólogo o el sociólogo intentarán bucear en el sentido social del derecho, y en su impacto dentro del contexto socio-cultural más inclusivo. Por tal motivo, desde la óptica de Ferrari la labor del jurista positivo es teórica y práctica, descriptiva y prescriptiva al mismo tiempo ya que señala vías a seguir. El sociólogo, en cambio, desempeña una labor sólo teórica y descriptiva, elaborando diagnósticos que eventualmente influirán en los que tienen poder de decisión, juristas incluidos. ${ }^{3}$

No obstante, no todos los sociólogos del derecho sostienen esta posición de autonomía relativa de su materia de análisis y, desde nuestra perspectiva, consideramos necesario una visión crítica de la misma.

En tal sentido, Manuel Atienza (2007) señala dos características innegables del concepto de derecho: ubicuidad y ambigüedad. La omnipresencia del derecho en nuestras sociedades no sólo está dada en lo que está regulado jurídicamente sino también en todo aquello que potencialmente puede llegar a estarlo. Bien sabemos, en este sentido, el efecto colonizador del derecho sobre las relaciones sociales. Sin embargo, la intervinculación entre norma, sanción, órgano de aplicación y Estado que caracteriza la concepción clásica del derecho no puede hacerse extensiva a otras modalidades de regulación social. Comprendiendo el derecho en tanto fenómeno situado históricamente, y siempre relativo a sociedades puntuales, el tema de la juridicidad pierde su carácter abstracto. En efecto, las mal denominadas comunidades primitivas, el derecho internacional, los grupos religiosos (derecho canónico incluido) y otras asociaciones cuyas regulaciones mantienen una independencia relativa de las reglamentaciones de los Estados conforman para Atienza claros argumentos sobre la imposibilidad de brindar una definición inequívoca acerca del concepto derecho.

Pero aún instalándonos en el espacio del derecho emanado desde el Estado, el espacio de la justicia ordinaria, tampoco la relación entre derecho y normas es pacífica. Desde una perspectiva normativista, mayoritariamente dominante entre los juristas, hablar de derecho es hacer referencia a la existencia de normas jurídicas, sean éstas leyes en sentido amplio, contratos o sentencias $\mathrm{y}$ otras resoluciones provenientes de órganos judiciales $\mathrm{o}$ administrativos. Las normas jurídicas se diferencian de las normas morales o religiosas por su poder de coacción social al determinar sanciones de carácter externo -utilización de la fuerza física-, y por la presencia de órganos de aplicación de las mismas (jueces, policía, etc.). Al hilo del análisis de Atienza el derecho trasciende esta dimensión normativa. En tal sentido, forman parte también del derecho las instituciones tales como parlamentos, juzgados y prisiones, los funcionarios de la Administración de justicia y los fines y las valoraciones que subyacen a todo ese entramado institucional.

En igual dirección se desplaza Mario Gerlero (2006) al argumentar que la sociología del derecho centra su interés en el influjo recíproco entre el ordenamiento jurídico y la realidad social, y más aún cuando los cambios sociales acentúan la brecha entre ambas dimensiones. Partiendo, entonces, del derecho como producto cultural, como resultado de los campos

\footnotetext{
${ }^{3}$ Cabe destacar que esta posición tiene su base en una clara distinción entre ciencia del derecho y sociología del derecho. La posición de Vincenzo Ferrari abreva en las perspectivas de Max Weber y Hans Kelsen. No obstante, y tal como él mismo destaca, su postura no es aceptada por todas las corrientes del pensamiento jurídico.
} 
interaccionales donde se ponen en juego los intereses sociales de los sujetos y desde donde se produce y reproduce el derecho, el autor señala (2006:14):

\begin{abstract}
"A la Sociología Jurídica o Sociología del Derecho la consideramos, entonces, como la ciencia que, a partir de la Sociología, describe, explica, interpreta y predice las causas, el desarrollo y las consecuencias de las relaciones y las diferencias existente entre la conducta del actor social, las expectativas informales $y$ las expectativas formales en el sistema socio-jurídico.

Nuestra disciplina, en su definición, toma a los actores (personas o grupos de personas) y las expectativas sociales informales (que surgen de los usos y costumbres) y formales (la normativa jurídica), para analizar las características de la interacción entre esos elementos". (énfasis en el original).
\end{abstract}

Bien conocemos que la relevancia de la institucionalización de la vida social otorga un lugar central al derecho debido a su potente andamiaje organizacional (Gómez Pellón, E.: 1999). No obstante, y siguiendo el análisis de Gerlero, es necesario recuperar el estudio de las conductas y relaciones sociales del individuo donde se ponen en juego las interpretaciones del derecho que hacemos cotidianamente en nuestro contexto socio-jurídico. El análisis de la acción social, esto es, el campo de las expectativas, interpretaciones, producciones y reproducciones que los sujetos realizan del derecho transforman a la sociología del derecho en el estudio de la realidad social, cuya referencia necesaria es el sistema normativo y la valoración de su impacto en el terreno de las interacciones cotidianas de los sujetos sociales. Si como expresa Carlos Lista (2000) la sociología es una ciencia cuyo objeto de estudio es la interacción social (con la inmensa complejidad que esta caracterización conlleva), la sociología del derecho en su especificidad da cuenta de la dinámica de las interacciones sociales en relación al derecho.

Por su parte, desde la óptica de Boaventura de Sousa Santos (2006), en las primeras décadas del siglo XX la sociología del derecho estuvo dominada por una visión normativista que a su vez privilegiaba el derecho sustantivo sobre el derecho procesal. Recién en la posguerra tiene lugar la apertura hacia una concepción del derecho que contempla sus dimensiones procesales y organizacionales. La profunda dicotomía entre law in books/law in action en la sociología norteamericana permitió la confrontación entre el derecho formalizado vigente y su eficacia en la dimensión de las relaciones sociales. Las condiciones teóricas que posibilitaron la mencionada apertura fueron, desde el análisis del autor, el desarrollo de la sociología de las organizaciones -con los aportes de Max Weber entre sus inspiradores-, el desarrollo de la ciencia política -y muy particularmente la teoría de los sistemas aplicadas al sistema judicial- y el desarrollo de nuevas perspectivas en la antropología del derecho de cara al proceso de descolonización -el desplazamiento del análisis de las normas hacia los procesos-. Asimismo, las condiciones sociales que coadyuvaron en esa dirección deben encontrarse en las luchas sociales de diversos colectivos -negros, estudiantes y sectores medios que exigían reivindicaciones sociales para la mejora de su calidad de vida-, en la crisis de la administración de la justicia en los años sesenta -importante aumento en el volumen de litigios debido a los altos índices de conflictividad social- y en su agravamiento en la década del setenta debido a la recesión económica y la imposibilidad del Estado de mantener su política asistencialista. Este panorama socio-económico posibilitó la atención de los estudios socio-antropológicos hacia la administración de justicia, el ámbito de los tribunales, las profesiones jurídicas -capacitación y reclutamiento de magistrados, por ejemplo-, y las ideologías políticas de los funcionarios de la administración de justicia, entre otras temáticas.

El derecho en el horizonte de la globalización:

Comprender las profundas transformaciones que el derecho viene experimentando de cara al impacto que la globalización ha significado en su campo, nos permite analizar los marcados procesos de cambio en las administraciones de justicia donde los estados nacionales 
conforman nodos en el marco de una red global. Que el derecho desde varias décadas atrás ya no es el mismo es un fenómeno fácilmente observable, lo difícil, en todo caso, es repensar desde la teoría social cómo afinamos las herramientas tanto teóricas como metodológicas para dar cuenta de estas transformaciones, y de su impacto en escenarios específicos. Por tal motivo, el punto de partida para el análisis del campo del derecho ya no consistiría, desde nuestra perspectiva, en el despliegue de conocimientos de otras disciplinas que a manera de haces de luces iluminan el complejo andamiaje que suponen las leyes y los procedimientos que lleva a cabo la justicia. El derecho es en sí mismo un espacio socio-antropológico que, además, contiene normas y procedimientos.

Pero ¿de qué cambios estamos hablando?. En otro espacio (Rodríguez, Graciela:2003) se ha señalado, retomando el análisis de P. Mercado Pacheco (1999), el nuevo orden jurídico que supuso el proceso de desterritorialización de la economía en el marco de un mercado sin fronteras donde los estados nacionales van perdiendo control sobre sus territorios y sus riquezas. En efecto, hicimos referencia a la emergencia de "Estados comerciales abiertos", y su inevitable impacto en diferentes ámbitos: (i)- en el ámbito del mercado de bienes y servicios donde el comercio entre Estados nacionales se ve paulatinamente reemplazado por un comercio entre empresas cuya proyección es internacional, (ii)- en el ámbito del mercado de capitales donde se impone la emergencia de las operaciones en bolsa a escala mundial y de la inversión financiera y (iii)- en el ámbito del mercado de trabajo donde se liberaliza la movilidad en las contrataciones y despidos en el seno de los Estados nacionales, por un lado, y se endurecen las reglamentaciones para los trabajadores inmigrantes de países pobres o empobrecidos, por otro. En tal sentido, y con relación al derecho, opera un doble movimiento en los países receptores de mano de obra: por un lado, pierden capacidad de intervención en las regulaciones del mercado financiero internacional $\mathrm{y}$, por otro, robustecen sus legislaciones nacionales para rebajar los derechos civiles y sociales de los trabajadores extranjeros.

Estas transformaciones, asimismo, impactan claramente sobre el derecho naciendo nuevos modelos de contratos a escala planetaria con el propósito de uniformizar y regular los mercados internacionales. Esta lex mercatoria es, entonces, de carácter transnacional y no es el producto de legislaciones nacionales sino de grupos empresariales. Asimismo, estos mismos grupos crean sus propias modalidades de dirimir conflictos, ya sea a través del arbitraje privado o la resolución de conflictos extrajudiciales, dando nacimiento a un nuevo derecho que no responde a las legislaciones estatales, y cuyo funcionamiento es independiente a su acogida o no por los Estados nacionales.

En este orden de ideas, también la formación profesional del abogado demanda nuevas destrezas vinculadas a un sólido manejo en el campo de los negocios que impone el efecto globalizador: incremento de sociedades anónimas y bancas que demandan para su regulación de nuevas legislaciones comerciales. ${ }^{4}$

Del mismo modo, y en el otro ángulo de la justicia, la justicia del ciudadano de a pie, la de las constantes dilaciones, la de la insalvable desproporción entre el volumen de casos a resolver y el número de juzgados, también se observan transformaciones. A. Garapon (1997), hace ya más de una década, hacía referencia al surgimiento de "diferentes focos de juridicidad". Esto supone una descentralización del derecho a través de nuevos servicios para resolver conflictos. En esta dirección, los servicios de mediación, con sus variados matices, representan modalidades no adversariales de hacer justicia sin acudir al ámbito tribunalicio. En estos espacios también devienen en "operadores del derecho" profesionales de la psicología y el trabajo social, entre otros.

\footnotetext{
${ }^{4}$ Esta reacomodación profesional del abogado es analizada en el ámbito europeo a través de las exigencias que manifiestan poderosos estudios jurídicos a la hora de reclutar abogados. Las necesidades de asesoramiento que requiere el empresariado ante la conformación de mercados más abiertos y más complejos obligan, por ejemplo, a una mayor capacitación en el campo profesional de la Auditoría de Cuentas (Grassi, G.:1999).
} 
En definitiva, nuevos sujetos de derecho, nuevas normas y nuevos procedimientos marcan una renovada manera de entender el derecho bastante distante de la clásica visión dicotómica entre "hechos" y "normas".

\section{2- La mirada antropológica al campo del derecho}

En un relevante trabajo de síntesis María Teresa Sierra y Victoria Chenaut (2002) recorren los desarrollos contemporáneos de las teorías antropológicas que intentan dar cuenta del ámbito de lo jurídico. ${ }^{5}$ Además de los aportes de las producciones norteamericanas, la antropología jurídica inglesa dentro del ámbito europeo ha tenido, y tiene, un lugar destacadísimo. De la mano de John Comaroff y Simon Roberts las autoras dan cuenta de los dos paradigmas que han ejercido mayor impacto en la academia anglosajona: el paradigma normativo y el paradigma procesual. A continuación anotaré los lineamientos muy generales de los mismos:

(i)- Paradigma normativo: aquí el acento radica en el conocimiento de las normas y es clara su vinculación con el positivismo jurídico formalista (la ciencia del derecho está construida por un sistema de normas interconectadas creadas por el legislador). En el campo de la antropología esta concepción tuvo sus mayores exponentes en las figuras de A. R. Radcliffe Brown, E.E. Evans Pritchard y Leopold Pospisil, entre otros. Funciones, roles y autoridad centralizada marcan el estudio del derecho en tanto campo de sanciones legales. Las políticas europeas en los territorios coloniales brindaron, por otra parte, el marco histórico de estos debates, constituyéndose el análisis de las costumbres de los pueblos colonizados en una temática no sólo de relevancia científica sino también política.

(ii)- Paradigma procesual: dominó la segunda mitad del siglo pasado y responde al proceso de descolonización. El antecedente lejano (años 20) es el análisis malinowskiano de los nativos de las islas Trobriand de Nueva Guinea. En esta línea de pensamiento la presencia del derecho no requiere de una fuerte institucionalización (gobierno centralizado, autoridades de aplicación, etc.). En los sistemas de prestaciones mutuas de bienes y servicios y de reciprocidades encontramos las modalidades de regulación social. De allí la importancia de centrar el análisis, antes que en las instituciones, en los procesos sociales. A partir de este desplazamiento en el enfoque del derecho, el campo analítico de los antropólogos privilegió la arena de las disputas vista no ya desde la autoridad judicial sino desde la perspectiva del litigante. El arreglo entre partes para la gestión de los conflictos dio lugar a robustas producciones sobre el análisis de casos de resolución de disputas o conflictos en las décadas de los setenta y los ochenta. En este orden de ideas, las normas legales brindaban una información relevante sobre las conductas deseables, sin embargo, el foco de análisis estaba centrado en el comportamiento de los individuos o grupos de individuos involucrados en la disputa -la aceptación, la indiferencia o la resignificación del orden normativo-. A diferencia del paradigma anterior el universo de las disputas no se consideraba como una desviación del orden social instituido.

Asimismo, tuvo lugar en estas décadas de los setenta y los ochenta el análisis de las modalidades alternativas de resolución de disputas o conflictos en el horizonte de la interculturalidad. A tal efecto, emerge con fuerza el Pluralismo Jurídico desde donde se

\footnotetext{
${ }^{5}$ En la denominada antropología clásica la dimensión jurídica de las sociedades conformaba un aspecto más de su organización socio-cultural. En los estudios antropológicos en sociedades no occidentales el aporte de interés ha sido el análisis de las regulaciones sociales en diferentes ámbitos -distribución de mujeres, de bienes, de obligaciones, regulación de la descendencia y de la herencia-, estrechamente ligados a una sacralidad que, en ocasiones, encapsulaba el orden y el contenido de las normas de derecho. En tal sentido, la perspectiva de una alteridad en el ámbito jurídico enriqueció las discusiones de la antropología social en su conjunto: las polémicas en torno al particularismo/universalismo, los alcances del método comparativo con relación a la extrapolación de categorías analíticas, cuestiones de ética e intervención profesional, entre otros núcleos teóricos y metodológicos.
} 
cuestiona nuevamente la concepción del derecho ligada a la visión monista en la relación derecho/Estado. De todos modos es recién hacia fines de los ochenta y en el transcurso de los noventa donde las visiones pluralistas del derecho abordan con análisis renovados el campo de las disputas iniciado en esta etapa de los estudios procesuales.

En suma, estos extremos del arco teórico: las posiciones estructuralistas y funcionalistas dominantes en la perspectiva normativista, por un lado, y las perspectivas interaccionistas más recostadas en las dinámicas de los procesos, por otro, posibilitaron la elaboración de nuevas propuestas en el abordaje antropológico del derecho.

(iii)- De la dominación a la resistencia: nuevas concepciones acerca del derecho

Sierra y Chenaut (op.cit) analizan, a la luz de las reivindicaciones de género, clase, raza, religiosas y étnicas de mediados de los ochenta y de los noventa, la concepción dual que asume el derecho: poder y resistencia al mismo tiempo. Al respecto las autoras señalan (p.151):

"Es justamente esta realidad uno de los motores del cambio jurídico y de las dinámicas sociales en distintas sociedades. Desde esta perspectiva, el derecho como el poder son vistos como una relación social y no como un estado de cosas. Las disputas como expresión de conflictos amplios de larga duración, contextualizadas histórica y socialmente, se consideran espacios de performance y de producción cultural que siguen siendo referentes claves para estudiar el poder, su negociación y contestación, y la manera en que el significado se construye y es atravesado por las dinámicas de poder y cambio jurídico en distintas sociedades." (cursiva en el original).

Esta concepción que contempla la capacidad dual del derecho, poder y resistencia social al mismo tiempo, se puso de manifiesto en las décadas de los ochenta y los noventa con la explosión de diferentes movimientos sociales en el espacio latinoamericano. En tal sentido,. los conceptos de identidad, resistencia y cultura vinculados a los reclamos "al" derecho y "por" nuevos derechos han sido trabajados profusamente en el ámbito de los estudios socioantropológicos. En efecto, en aquellas elaboraciones emergieron con fuerza los análisis de las conformaciones de diferentes procesos identitarios cuyas reivindicaciones respondían a problemáticas de género, étnicas, de defensa del medio ambiente y de lucha por la recuperación de la memoria histórica, entre otras (Bigot, M., Rodríguez,G., Vázquez.,Héctor:1992),. En este marco, las visiones sobre la diversidad y la pertenencia también son resignificadas en el escenario de un mundo inexorablemente interconectado, donde la petición por nuevos derechos consolida un perfil de ciudadanía que procura robustecer los valores de la inclusión y la democracia.

En este orden de ideas, y retomando el impacto que estas dinámicas sociales imprimió al derecho y a la concepción del mismo por parte de las sociedades, consideramos oportuno destacar la consolidación del Pluralismo Jurídico con nuevos abordajes para su análisis y la implementación de mecanismos de resolución de disputas o conflictos desde las administraciones estatales.

En tal sentido, en otro espacio anotamos (Rodríguez, G.:2006) que la noción de Pluralismo Jurídico se halla estrechamente interconectada con la problemática del acceso a la justicia y de su redistribución equitativa. En términos generales también señalamos que hacer referencia a una visión plural del derecho supone como punto de partida una visión plural de la sociedad. La presencia de múltiples centros de decisión, de otros sujetos sociales en juego (más allá de los funcionarios de la justicia ordinaria) y de procedimientos diferenciales para dirimir disputas ponen en tela de juicio la reducción del derecho a una única naturaleza. No obstante, el reconocimiento de este "policentrismo jurídico" no significa, al menos necesariamente, que estos campos jurídicos sean totalmente autónomos. A diferencia del pluralismo jurídico de la primera hora (también denominado "viejo pluralismo"), donde se analizaban los derechos de los nativos en los países coloniales como derechos paralelos a los sistemas jurídicos de las 
potencias colonizadoras -de igual modo se abordaron los derechos consuetudinarios de los aborígenes americanos-, las visiones renovadas sitúan el análisis en la arena de la interlegalidad. En efecto, las costumbres jurídicas de los pueblos indígenas están interferidas por los derechos estatales, y se advierte un claro sincretismo ya sea en la resolución de conflictos en el espacio del endogrupo o en los fallos de los jueces cuando incorporan en sus motivaciones elementos de derechos consuetudinarios. Asimismo, la mediación, y máxime si es en materia de consumo, no se halla al margen del derecho emanado desde el Estado. Estas disputas adquieren el cariz de situaciones problemáticas que se resuelven pragmáticamente, y el acento no está tanto en el contenido de las normas como en los procedimientos, en las metodologías empleadas fuera del espacio tribunalicio. La implementación de estos nuevos mecanismos y su creciente aceptación por los ciudadanos además de transformar el concepto de derecho también impacta sobre la visión acerca de la justicia.

En este contexto son los mismos poderes políticos los que producen discursos que intentan acercar la justicia a la ciudadanía, con la clara intencionalidad de despojarla de una imagen ligada al poder para acercarla a una concepción de servicio público. Esta idea de una justicia para todos y al servicio de todos se enmarca dentro de los intentos de modernización del poder judicial en los países de la región y, en esta dirección, la problemática del acceso a la justicia cobra centralidad. De este modo, cuando se alude a la necesidad de una reforma judicial la cuestión transita en la identificación del "para qué, por quién, para quién y cómo" deben operar las reformas para fortalecer, entre otras cuestiones, un mejor y mayor acceso a la justicia (Garro, Alejandro: 2006, pp.27/28). Esta necesidad de ampliar el acceso pone el acento en los sectores más vulnerables de la sociedad, tanto desde el punto de vista económico-social como cultural.

Al hilo de estas ideas M. Fernández Valle (2006) resalta el papel de las políticas públicas en la programación de reformas judiciales en función de mejorar institucionalmente la oferta de justicia a través del incremento de tribunales, la informatización de los juzgados, la transparencia en la administración y en la búsqueda de mejores criterios en el reclutamiento de funcionarios. No obstante, estas políticas no alcanzan para impactar favorablemente en aquellos sectores despojados de todos los recursos para el mínimo acceso al andamiaje institucional. Estos sectores requieren de un repertorio complementario de reformas donde el acento debe estar puesto, siguiendo la argumentación de Fernández Valle, en el acceso a la información jurídica sobre el conocimiento de los derechos y los modos para que sean reconocidos y respetados, en nuevas redefiniciones del sistema de asistencia jurídica gratuita (revisiones en los criterios de admisión), en la promoción de acciones judiciales colectivas y en el fortalecimiento de la participación ciudadana a través de la creación de políticas públicas para el mejoramiento de la justicia.

En tal sentido, y como respuesta a las críticas desde las voces ciudadanas sobre la lentitud de la justicia, su lenguaje incomprensible y la corrupción que permea sus diversos estamentos se impone la creación de nuevas modalidades de hacer justicia. En esta dirección, la necesidad de rebajar el volumen de casos que atienden los juzgados, causa central de las graves dilaciones en el dictado de las sentencias, y de acercar al ciudadano hacia formas más descentralizadas de resolver conflictos requiere del empleo de metodologías más rápidas y menos onerosas de resolución de conflictos. Se potencia, entonces, el campo de la resolución de disputas de forma no adversarial.

Un ejemplo cercano a estas nuevas formas de llegar al ciudadano fue el tenor del discurso del presidente de la Corte Suprema de Justicia de Santa Fe, Roberto Falistocco, en un intento por desacralizar la imagen de la justicia con motivo del acto de inauguración del año judicial en febrero de $2009^{6}$. En efecto, el orador hizo referencia a la necesidad de adecuar el lenguaje de la justicia en aras a una mejor comprensión por parte del ciudadano de las decisiones judiciales. En tal sentido, esta justicia más abierta también debe ser ágil y menos burocrática debiéndose

\footnotetext{
${ }^{6}$ Nota publicada en el periódico Página 12. Sábado 21 de febrero de 2009. http://www.pagina12.com.ar/imprimir/diario/suplementos/rosario/10-17392-2009-02-, al 31/08/2009
} 
erradicarse "la cultura del pleito por el pleito mismo, por cuanto existen otros mecanismos que permiten solucionar los conflictos de forma más ágil y menos burocrática que mediante el juicio habitual, como la mediación". En esta dirección, su expresión "Los Tribunales deben ser de puertas abiertas" marca el giro hacia una idea de justicia en tanto prestadora de servicios a la ciudadanía.

\section{3 -Símbolo, ritual, espacio y emociones en el abordaje del campo del derecho y la justicia}

"...justice must not only be done, it must also be seen to be done"

(Berman, H.J.:1993:9)

Las perspectivas meramente instrumentales en los análisis del derecho y la justicia, donde los ejes sólo están puestos en los grupos de poder y en la fuerza de coacción, resultan insuficientes a la hora de dar cuenta del impacto que tienen en el ciudadano los diferentes entornos desde donde se produce el derecho y se toman las decisiones judiciales.

En esta dirección, A. Garapon (1985) plantea la estrecha relación del espacio judicial con la idea de sacralidad. Apoyándose en la fenomenología de las religiones y en la concepción durkheimiana de lo sacro, el autor parangona el fenómeno religioso con el fenómeno jurídico. Las prácticas que tienen lugar en ambos espacios conforman acciones ritualizadas y actúan como centros ordenadores del espacio profano, regulándolo y otorgándole una referencia. Esta comparación permite comprender la semejanza entre la arquitectura religiosa de las iglesias y la arquitectura judicial que ha caracterizado a los Palacios de Justicia. El simbolismo esculpido en sus fachadas y en sus puertas (presencia de hombres, animales o dioses que a modo de guardianes reflejan la idea del aspecto monstruoso, terrible y misterioso de lo sagrado) y su enclave elevado en el diseño urbano con presencia de majestuosas escalinatas, a modo de ascensión espiritual, ponen de manifiesto que tanto la función religiosa como la función judicial transcurren en lugares extraordinarios, separados del mundo ordinario, de sus tiempos y espacios cotidianos. En igual sentido, no menos importante es la comparación que realiza el autor entre los altares y las Salas de Audiencias o de Vistas. La presencia de barreras donde en éstas últimas se divide el espacio del público de aquel donde se celebra el juicio pueden compararse con las divisiones que separan el altar del espacio ocupado por los fieles en las iglesias cristianas. En los espacios interiores los estrados y los lugares reservados para el sermón delimitan el papel y las acciones de sus participantes.

J. Brigham (1987:15) sintetiza la presencia de esta galeria de símbolos en el espacio judicial con estas palabras:

"In law, the bench, the robes, and the marbled walls signal that something is going on, and that the activity is important. We know that these "things" are not just physical, but we treat the physical presence as the institution".

Espacios jerarquizados y acciones ritualizadas en el ámbito judicial ponen de manifiesto el profundo simbolismo de estas arquitecturas en la prevalencia del derecho por sobre la fuerza, en la búsqueda de la sumisión de lo individual al orden social. Se trata, en definitiva, de una experiencia sensorial que apela al mundo de las emociones. En igual sentido, el mismo lenguaje jurídico depura las contradicciones y la opacidad de la realidad transformándolas en categorías operacionales que asignan lugares y comportamientos pautados. El repertorio de gestos, palabras y fórmulas consagradas que todo proceso judicial conlleva logra expresar el conflicto preservando el orden y neutralizando la contradicción (Rodríguez, G.:2000).

En esta dirección también se desplaza H. Berman (1993) al señalar que, aun en el marco del proceso de secularización del derecho, unido al concepto de racionalidad actúa el componente 
emotivo. Desde su perspectiva, la presencia de este componente emocional permite la comparación de la dimensión jurídica con la religiosa en cuatro aspectos:

(i)- ritual: ligado al ceremonial como símbolo de la objetivación de la ley; (ii)- tradición: en tanto prácticas y lenguaje heredados del pasado que simbolizan la continuidad del derecho; (iii)autoridad: relacionada con las fuentes, habladas o escritas, decisivas en sí mismas y símbolos de la obligatoriedad del poder de la ley y (iv)- universalidad: conectada con la búsqueda de conceptos universalmente válidos enlazados con la idea de verdad. Estos aspectos conforman el contexto de legitimación del derecho. Y son, precisamente, los rituales del derecho en sus diferentes instancias -legislación, administración y negociación- los que pueden parangonarse con los rituales religiosos. En ambos se invocan valores considerados útiles para la sociedad y que, además, conllevan una profunda creencia emotiva. En palabras del autor (p.13):

“...legal emotions share with religious emotions the same sense of 'givenness', the same reverence, the same urgency. In secular religions the givenness, the sanctity, may be attached to the state rather than to God, or to the court, or to the party, or to the people".

A continuación presentamos, sucintamente, los aportes de C. Geertz y L. Cardoso de Oliveira, los cuales desde el campo de la antropología dan cuenta de la importancia de incorporar las percepciones, los significados y las emociones que los ciudadanos experimentan con relación al derecho y la justicia.

- El fenómeno jurídico como universo simbólico: las sensibilidades legales en un análisis semiótico de la cultura

El análisis de las "sensibilidades legales" en C. Geertz (1994) no tiene su punto de partida en los postulados normativos sino en la trama de relaciones sociales y culturales que le otorgan sentido. En otro espacio (Rodríguez, G:1996) analizamos la propuesta del autor como un claro intento de explorar las estructuras de significación mediante las cuales los hombres construyen sus propios mundos, organizando su convivencia a través de mecanismos punitivos que tienen en su base visiones específicas del "deber ser" y del "deber hacer". El derecho, desde esta perspectiva "forma parte de una manera característica de imaginar lo real" (Geertz.C: op.cit, p.213). Su análisis de las diferentes "sensibilidades legales": islámica, índica y del sector malayo de la Malayo Polinesia tienen como común denominador evitar la separación entre hecho y ley tal como sucede en nuestro derecho. La conexión profunda entre ambas instancias de derecho se halla muy presente en la tradición islámica y, a su vez, la visión legal índica muestra una relatividad manifiesta en el ordenamiento de los derechos y las obligaciones, ya que ambos se hallan condicionados a la posición que detenta el individuo en su sociedad. En tal sentido, no son iguales las conductas deseables en un guerrero, un ermitaño o un sacerdote. La metodología analítica de Geertz, que él mismo caracteriza como hermenéutica cultural o semántica de la acción, implica un ejercicio de descentramiento de nuestras posiciones para lograr interpretar otras concepciones del derecho a través de un diálogo que actúe como fusión de horizontes en las instancias de interlocución. Esta búsqueda del "sentido" de los acontecimientos, como él mismo lo declara, presupone un alejamiento de la reflexión funcionalista acerca del derecho en tanto mecanismo que evita conflictos, que defiende a los sectores vulnerables de los intereses de los poderosos o, por el contrario, que preserva la fortaleza socio-económica de éstos últimos.

Desde la visión de E. Krotz (2002:37:38) la modalidad geertziana de conocer "desde dentro" el derecho en tanto fenómeno social puede considerarse ..."como un acercamiento muy sugerente al estudio de los fenómenos jurídicos, pues éste no se limitaría al registro de acciones y la recolección de expresiones verbales, sino se interesaría también por el mundo de las ideas, los estereotipos, las predisposiciones, las expectativas, las emociones y las evaluaciones 
conscientes y comunicables que realizan los integrantes del grupo bajo estudio". (cursiva en el original)

\section{- "Reconocimiento" y "reciprocidad" en el campo de las disputas}

En el trabajo de Luis. R. Cardoso de Oliveira (2004) se analizan los procesos de resolución de disputas a través de la articulación de las nociones de honor, dignidad y reciprocidad. Este análisis reviste particular interés ya que involucra la temática de las percepciones y emociones del ciudadano en sus demandas por reconocimiento de su dignidad. Al hilo de estas ideas, el autor analiza la carencia de un marco institucionalizado que contemple el menoscabo a la integridad y dignidad del ciudadano a través del insulto moral, por ejemplo, como una agresión objetiva y pasible de un acto de reparación. En el marco de su investigación en los Juzgados de Pequeñas Causas de Estados Unidos y en Juzgados Especiales en Brasil el autor centra su interés en la percepción de los distintos actores que forman parte del proceso de disputas: la visión de los litigantes de sus derechos, sus intereses y del mismo procedimiento judicial llevado a cabo como, asimismo, la percepción de los jueces con relación a su labor en estos procesos de resolución de causas. En este contexto, el acento está puesto no sólo en los derechos e intereses de los litigantes sino también en los derechos de reconocimiento que nos conectan con la dimensión moral de las disputas, razón por la cual el autor rescata el potencial interpretativo del don y su relación con las obligaciones recíprocas y el orden moral presente en la obra de Marcel Mauss. En tal sentido, y considerando que en la instancia del reconocimiento está en juego la integridad de la identidad personal más que otras cuestiones de carácter utilitario y que, además, es la instancia menos considerada en el proceso judicial Cardoso de Oliveira (p.34) señala:

\footnotetext{
"Dado que la calidad de la interacción entre las partes en conflicto tiende a constituirse en un aspecto importante de las causas, tal como es expresado en los discursos de los actores, sería deseable que cuestiones como lazo social, identidad y reciprocidad fueran asociadas a la preocupación por los derechos, los intereses y la ciudadanía. De este modo, es importante captar no sólo el sentido de las interpretaciones ofrecidas por los actores y sus justificaciones, sino también cómo ellos se sitúan en relación con los problemas abordados en el plano de los sentimientos".
}

Tanto la visión del derecho en Geertz como las nuevas miradas de Cardoso de Oliveira hacia el espacio de las disputas, apenas anotadas en el marco de este trabajo, constituyen otras formas de pensar el derecho en sintonía con lo que la gente percibe y siente cada vez que se ve involucrada en una disputa judicial. A modo de cierre consideramos importante destacar estos aportes que junto con los análisis sobre los espacios y rituales judiciales enriquecen el campo de los estudios socio-jurídicos.

\section{Palabras finales:}

.Hemos sistematizado críticamente las líneas teóricas más relevantes sobre las concepciones acerca del derecho y la justicia, sin pretender abarcar todas las aproximaciones posibles. En el marco de esta diversidad de enfoques y abordajes se ha puesto el énfasis en el espacio de los análisis antropológicos. En tal sentido, los profundos cambios que ha experimentado y experimenta el ámbito de lo jurídico requieren de los analistas sociales reflexiones continuas sobre la naturaleza epistémica de su campo de estudio.

En este orden de ideas, la incorporación de la visión ciudadana propicia una mejor comprensión del impacto del derecho en la cotidianeidad de la gente. A su vez, la importancia cada vez más 
creciente de los servicios de mediación en países como el nuestro constituye un reflejo de las nuevas necesidades sociales. El desplazamiento de la concepción de la justicia como poder a una visión de la justicia como prestadora de servicios al ciudadano se halla cada vez más presente en el discurso de los funcionarios del poder judicial. Por último, la incorporación en los análisis de los sentimientos y emociones de los ciudadanos ayudaría a comprender con mayor profundidad, por un lado, la innegable incidencia del derecho en nuestras vidas y, por otro, los reclamos sociales con relación a su funcionamiento.

\section{Referencias bibliográficas:}

ATIENZA, Manuel (2007): El sentido del Derecho, Ariel, Barcelona,

BERMAN, H.J.(1993): Faith and Order. The Reconciliation of Law and Religion, Studies in Law and Religion, Scholars Press, Atlanta, Georgia.

BIGOT, Margot, RODÍGUEZ, Graciela y VÁZQUEZ, Héctor (1992): “Acerca de la resistencia étnica y de la resistencia indígena" en: Papeles de Trabajo, $\mathrm{N}^{\mathrm{o}} 2$ Centro de Estudios Interdisciplinarios en Ciencias Etnolingüísticas y Antropológico Sociales, CICEA. TecnoGraf, Rosario. (pp.13-20).

BRIGHAM, j. (1987): The Cult of the Court, Temple University Press, Philadelphia.

CARDOSO DE OLIVEIRA, Luís R. (2004): "Honor, Dignidad y Reciprocidad" en Cuadernos de Antropología Social No 20, FFyL. -UBA-, Buenos Aires. (pp.25-39).

FERNÁNDEZ VALLE, Mariano (2006): "El acceso a la justicia de los sectores en desventaja económica y social" en: Acceso a la justicia como garantía de igualdad -Instituciones, actores y experiencias comparadas-, Haydée Birgin y Beatriz Kohen compiladoras, Editorial Biblos, Buenos Aires, Argentina. (pp. 39-58).

FERRARI, Vincenzo (2006): Derecho y Sociedad -Elementos de sociología del derecho-, Universidad Externado de Colombia, Argentina

GARAPON, Antoine (1985): L' ane' portant des reliques. Essai sur rituel judiciaire. Collection "Justice humaine", Èditions du Centurion, París.

GARAPON, Antoine (1997): Juez y Democracia -Una reflexión muy actual-, Flor del Viento, España.

GARRO, Alejandro M. (2006): La reforma judicial: ¿para qué, por quién, para quién y cómo? en:

Acceso a la justicia como garantía de igualdad -Instituciones, actores y experiencias comparadas-Haydée Birgin y Beatriz Kohen compiladoras, Editorial Biblos, Buenos Aires, Argentina. (pp.27-38).

GEERTZ, Clifford (1994): Conocimiento Local, Paidós, Barcelona. 
GERLERO, Mario Silvio (2006): Introducción a la Sociología Jurídica -Actores, sistemas y gestión judicial-, David Grinberg -Libros Jurídicos-, Buenos Aires.

GÓMEZ PELLÓN, Eloy (1999): "Aspectos fundamentales de la Antropología Jurídica” en Antropología Jurídica (Ignasi Terradas coords.) No 4. Federación de Asociaciones de Antropología del Estado Español y Asociación Galega de Antropoloxia -Actas del VIII Congreso de Antropología 20-24 de setiembre de 1999-, Santiago de Compostela, España (pp. 13-31).

GRASSI, Gisell (1999): Los grandes Bufetes de España. Empresas de prestigiosos profesionales. Tesina presentada al Master's Programme, Internacional Institute for the Sociology of Law. Antigua Universidad de Oñate, País Vasco, España.

KROTZ, Esteban (2002): "Sociedades, conflictos, cultura y derecho desde una perspectiva antropológica" en Antropología Jurídica: perspectivas socioculturales en el estudio del derecho,

Krotz, Esteban (ed.), Anthropos, Barcelona y Universidad Autónoma Metropolitana, México (pp. 13-49).

LISTA, Carlos A. (2000): Los Paradigmas de Análisis Sociológico, -Ciencia, Derecho y Sociedad Serie: Materiales de Estudio-, Facultad de Derecho y Ciencias Sociales -Universidad Nacional de Córdoba- Córdoba, Argentina.

MERCADO PACHECO, P. (1999): "Las transformaciones del Derecho en la Mundialización” en Capella Hérnández, J.R. (coord.), Consejo General del Poder Judicial, Madrid (pp.125-158).

RODRÍGUEZ, Graciela (1996): "Método Comparativo y Pluralismo Legal" en Papeles de Trabajo -Centro Interdisciplinario de Ciencias Etnolingüísticas y Antropológico-Sociales, CICEA, N5: TecnoGraf, Rosario (pp.35-40).

RODRÍGUEZ. Graciela (2000): Espacio, Ritual y Organización, El Palacio de Justicia de Vitoria, País Vasco. Tesina presentada al Master's Programme, Internacional Institute for the Sociology of Law. Antigua Universidad de Oñate, País Vasco, España.

RODRÍGUEZ, Graciela (2003): Una práctica social en movimiento: los jueces españoles. Colección Working Papers $\mathrm{N}^{\circ}$ 230. Separata publicada por el Instituto de Ciencias Políticas y Sociales -ICPS-. Barcelona.

RODRÍGUEZ, Graciela (2006): "Notas sobre el pluralismo jurídico desde la antropología y sociología jurídicas" en Papeles de Trabajo, -Centro Interdisciplinario de Ciencias Etnolingüísticas y Antropológico-Sociales, CICEA, Nº14 Centro Científico Tecnológico CONICET. Rosario (pp. 207-222.).

SANTOS, Boaventura de Sousa (2006): De la mano de Alicia -Lo social y lo político en la postmodernidad-. Siglo Del Hombre Editores y Ediciones Uniandes -Universidad de los Andes-, Bogotá.

SIERRA, María Teresa y CHENAUT, Victoria (2002): "Los debates recientes y actuales en la Antropología Jurídica: las corrientes anglosajonas" en Antropología Jurídica: perspectivas 
Papeles de Trabajo No20 - Diciembre 2010 - ISSN 1852-4508

Centro de Estudios Interdisciplinarios en Etnolingüística y Antropología Socio-Cultutal

socioculturales en el estudio del derecho, Krotz, Esteban (ed.), Anthropos, Barcelona y Universidad Autónoma Metropolitana, México (pp. 113-170). 